\title{
Saturation of the Cr-V ledeburitic steel with nitrogen
}

\author{
P. Jurči* \\ Czech Technical University, Faculty of Mechanical Engineering, Karlovo nám. 13, 12135 Prague 2, Czech Republic
}

Received 24 February 2010, received in revised form 19 April 2010, accepted 23 April 2010

\begin{abstract}
The P/M Vanadis 6 ledeburitic cold work tool steel was heat-treated and plasma nitrided. On processed material, microstructure, hardness and microhardness, nitrogen and carbon concentration depth profiles and phase constitution were investigated. The initial microstructure consists of a martensitic matrix and particles of carbides $\mathrm{MC}$ and $\mathrm{M}_{7} \mathrm{C}_{3}$. After plasma nitriding surface hardness and microhardness were increased due to the nitrogen diffused in the near surface region. Firstly, martensite is saturated with nitrogen. After the solid solubility limit is exceeded, also the MC- and $\mathrm{M}_{7} \mathrm{C}_{3}$-phases contribute to the total nitrogen uptake of the material. Finally, nitrides like the $\mathrm{Fe}_{4} \mathrm{~N}-$ and $\mathrm{Fe}_{3} \mathrm{~N}-$ and $\mathrm{CrN}$-phase, as well as nitride network and continuous compound layer are formed. The possible contribution of each structural constituent to the total nitrogen uptake of the steel is discussed.
\end{abstract}

K e y w o r d s: Cr-V ledeburitic steel, heat treatment, nitriding, microstructure, phase constitution

\section{Introduction}

Nitriding is besides carburizing the most widely used thermo-chemical heat treatment of iron-based materials. The industrial importance of the nitriding became great over the past four decades because it was found out that a properly done processing could improve tribological properties, fatigue properties and in the case of tool steels also the adhesion of thin ceramic layers made by PVD-processes [1-4].

There are various nitriding methods, e.g. gas nitriding, low-pressure nitriding, salt bath nitriding and plasma nitriding. But for high alloyed tool steels, mainly the ledeburitic steels, only plasma nitriding gives results, which are of a great interest, e.g. the surface hardness, hardness depth profiles, nitrogen saturation level, etc. are well reproducible. The reason is that the alloying elements, and chromium in particular, form stable oxides on the surfaces that hinder the nitrogen transfer into the material in the gas nitriding. In plasma nitriding, however, the oxides can be sputtered by the ion bombardment, making the surface well activated and the nitrogen can penetrate into the steel more easily.

The formation of nitrided region on pure iron in gas nitriding was described even several years ago precisely by Somers and Mittemeijer [5]. After exceeding the solid solubility limit of nitrogen in iron at a given temperature, the $\gamma^{\prime}$-phase begins to nucleate on the surface. The incubation period for nucleation depends on the flux of nitrogen atoms arriving at the surface (controlled by the level of ammonia dissociation in gas nitriding) on the one side and on the flux of the nitrogen atoms due to diffusion into the bulk on the other side. Nuclei of compounds then grow longitudinally to the surface and after that their thickening begins. Further growth of either $\varepsilon$ or $\gamma^{\prime}$ sub-layers is controlled by the solid-state diffusion through these phases, e.g. by the slowest process attending the nitriding procedure.

The formation of nitrided areas in the pure binary $\mathrm{Fe}-\mathrm{Cr}$ system was analysed in $[6,7]$. Vives Dias and Schacherl in these papers found out that up to $8 \mathrm{wt} . \%$ of Cr-content the nitrided layers consist of two types of original grains. The first ones look bright and are placed mostly far away from the surface. The grains of the second type are dark and are mostly adjacent to the surface. If the material contained more than 8 wt. $\% \mathrm{Cr}$, up to $20 \mathrm{wt} . \%$, then whole nitrided region consisted of the dark grains only. An explanation of these structural features is as follows: During the

* Tel.: + 420224357 275; fax: +420 224357 519; e-mail address: p.jurci@seznam.cz 
first stage of nitriding $\mathrm{CrN}$ precipitates were formed. They were of sub-microscopical size and were coherent with the matrix. As a consequence, the compressive stresses were formed parallel to the surface and hardness increased. After some period the precipitates underwent a coarsening or they were replaced in both cases a lamellar microstructure, consisting of the alpha-phase and CrN-lamellae, was formed. Continuous or discontinuous coarsening was accompanied with a decrease of hardness and relaxation of internal compressive stresses. For higher chromium containing material the formation of nitrided region began directly with the formation of lamellar structure with incoherent phases. This is connected with very moderate compressive stresses in the nitrided zone.

The nitrogen uptake by the iron- 2 wt.\% of vanadium system was examined by Hosmani et al. [8] and Vives Dias et al. [9]. They divided the total nitrogen uptake into several parts as: equilibrium soluble nitrogen in alpha-iron, nitrogen incorporated in the vanadium nitrides $\mathrm{VN}$, nitrogen dissolved due to the strain field induced by the misfit of lattices of $\mathrm{VN}$ and that of alpha-iron and finally to the nitrogen connected to the dislocations. In addition they reported that after the solid solubility limit of the nitrogen in alpha-iron was exceeded the VN-particles were formed. They were coherent with the matrix and induced strain fields around, responsible for high hardness of nitrided areas. The VN-nitrides were formed as very tiny, approximately 3-4 atom monolayer in thickness and several $\mathrm{nm}$ in length, platelets. Their small size remained also after long time processing and made their identification and evaluation very difficult.

Ledeburitic tool steels are mostly composed as poly-component materials, containing at least three or four main elements. Besides the iron they contain at least around 0.75 wt. $\%$ of carbon and not less than 4 wt. $\%$ of chromium. Most of them are alloyed also with various portion of vanadium and, in addition, the high speed steels also typically with tungsten and molybdenum. High alloying elements content is the principal source of serious obstacles in determining what happens when these materials are nitrided. The second difficulty in the assessment of the nitriding effect is the fact that also after usual heat processing, e.g. austenitizing, quenching and tempering to a secondary hardness peak, the ledeburitic steels have a poly-phase constitution. Carbon, together with alloying elements, forms various carbides. Some of them are soluble in the austenite during the heat treatment but other portion of carbides remains in the structure of heat-treated steels in the form of primary or eutectic phases, together with tempered martensite. The carbides are also capable to uptake some portion of nitrogen, especially in the cases if they are formed as so-called deficit. The total nitrogen uptake described in $[8,9]$ had then to be extended by the contribution of deficit carbides. Other portion of nitrogen is spent for the formation of nitrides that are formed during the processing. Nevertheless, not only disperse nitrides are formed via precipitation of their particles in the matrix but also continuous formations on the surface can be expected in real technological processes. Finally, also the carbon content in the tempered martensite, as a possible source of redistribution of interstitials during the nitriding, has to be taken into the consideration. The problem with the nitriding of ledeburitic steels is then much more complex than that of pure iron or binary, but mono-phase systems, and no complex experimental work has been devoted to assessing the nitriding process of these materials yet.

\section{Experimental procedure}

\subsection{Material}

The material used for the experiments was the Vanadis 6 ledeburitic steel produced by the powder metallurgy of rapidly solidified particles. The nominal chemical composition of the steel was $2.1 \% \mathrm{C}, 7 \%$ $\mathrm{Cr}, 6 \% \mathrm{~V}, \mathrm{Fe}$ bal. This choice was done for several reasons but mainly because

- the ledeburitic steel has a relatively simple chemistry;

- the use of rapid solidification technique for the material manufacturing enables us to eliminate problems with macro-segregation, structural anisotropy and related characteristics that can negatively influence the experimental results;

- the steels produced at Uddeholm AB are of a high degree of purity so that the effect of non-metallic inclusions like oxides, sulphides etc. on the mechanical properties (this investigation is also included in a complex experimental programme) can be disregarded.

\subsection{Processing}

The material was cut into cylindrical pieces of $18 \mathrm{~mm}$ in diameter and $4 \mathrm{~mm}$ in thickness. All the specimens were net-shape machined, polished and submitted to a heat treatment. The heat treatment consisted of the vacuum heating up to the austenitizing temperature of $1050{ }^{\circ} \mathrm{C}$, holding time of $30 \mathrm{~min}$ and nitrogen gas quenching. The pressure of nitrogen gas was 6 bar, i.e. as high as necessary to prevent the precipitation of pro-eutectoid carbides from the austenite. Immediately after quenching, a double tempering followed. The tempering temperature was $550^{\circ} \mathrm{C}$ and the time was 1 hour for each tempering cycle. Achieved hardness after such a heat treatment was $60 \mathrm{HRC}(700$ HV 10), i.e. recommended value for variety of industrial cold work applications.

Plasma nitriding processes were carried out on the 
RÜBIG Micropuls - Plasmatechnik device. Before nitriding the samples were sputtered in pure hydrogen for $30 \mathrm{~min}$. Standard nitrogen/hydrogen atmosphere with the $\mathrm{N}_{2}: \mathrm{H}_{2}$ ratio of $1: 3$ and a voltage of $460 \mathrm{~V}$ was used for all nitriding procedures. The processing temperatures were 470,500 and $530^{\circ} \mathrm{C}$ and processing times 30,60 and $120 \mathrm{~min}$.

\subsection{Investigation methods}

For microstructural examination the light microscopy and the scanning electron microscope were applied. Samples for light microscopy were standardly prepared, e.g. ground and polished with diamond paste, the last step with the $1 \mu \mathrm{m}$ diamond paste and etched with Nital-reagent and Murakami-reagent, to allow the separation of $\mathrm{M}_{7} \mathrm{C}_{3^{-}}$and MC-phases, respectively. The specimens for the scanning electron microscopy were prepared by two different methods. The first one was the standard metallographical preparation with a deep Nital-reagent etching, to enable to reveal important detail in carbides distribution in the material. The second type of the preparation was the ion polishing of smooth surfaces. This type of specimens was prepared mainly to allow the EDS analysis and identification of carbides. The micrographs as well as the EDS-mapping were done using an acceleration voltage of $15 \mathrm{kV}$. For the EDS mapping a surface current of $22.5 \mathrm{nA}$ was used.

The depth profiles of carbon and nitrogen were established with the WDX - microprobe analyser CAMEBAX-MICRO. Five measurements were made on each specimen and the mean values and standard deviations were calculated.

Hardness measurements using a Vickers method were performed using a Zwick hardness tester, applying a load of $10 \mathrm{~kg}$ for surface hardness and $50 \mathrm{~g}$ for hardness depth profiles determination. The depth profiles were measured on carefully prepared specimen cross-sections at an inclination angle with respect to the surface (bevelled specimens) of $12^{\circ}$, to improve the depth resolution. For details regarding the specimen preparation, see [10]. The distance between the adjacent indents was $20 \mu \mathrm{m}$, in order to avoid the influence of the plastically deformed zone surrounding the nearest two indents.

The phase constitution was investigated also with $\mathrm{X}$-ray diffraction. Standard Bragg-Brentano configuration was used. The two-theta diffraction angle was scanned in the range $25-105^{\circ}$. Phase identification was made by the comparison of measured diffraction peaks with the data from Pearson's [11].

\section{Results}

Light and SEM-micrographs in Fig. 1a,b show that
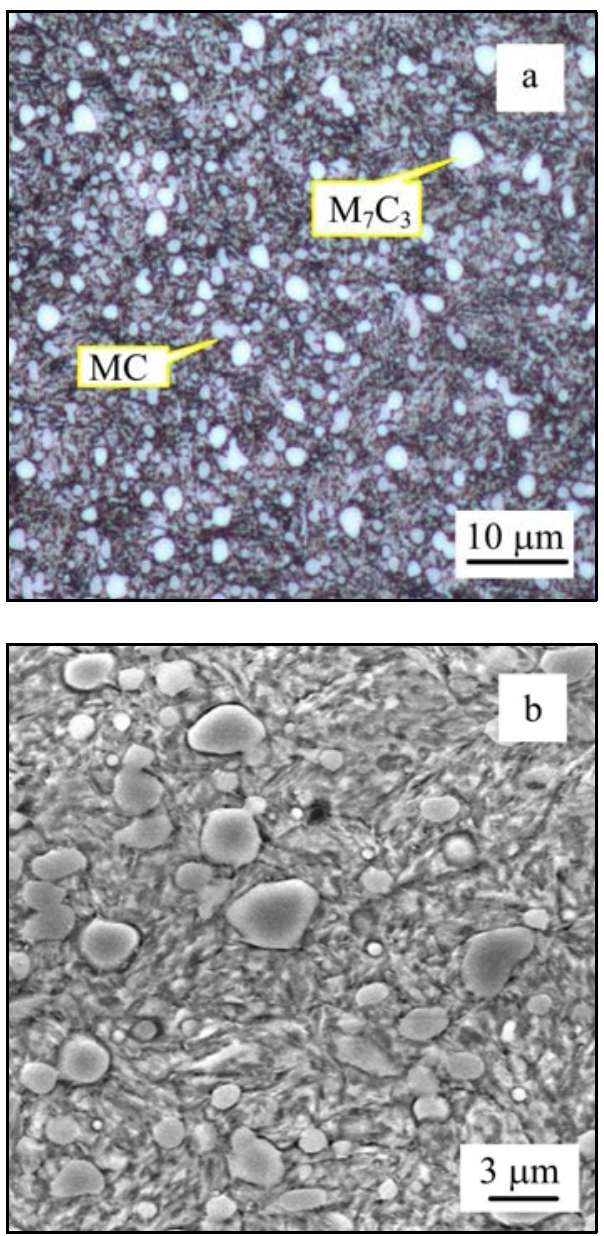

Fig. 1. Microstructure of the substrate material Vanadis 6 after heat treatment: (a) light micrograph, (b) SEM micrograph.

the microstructure of the substrate material consists of the matrix with fine, uniformly distributed carbide particles of regular, spherical shape and with a size of several microns. As shown in the micrograph, Fig. 1a, the carbides are of two basic types. The first ones are larger, white regular particles of the $\mathrm{M}_{7} \mathrm{C}_{3}$-phase. The second type is the MC-phase, visible as smaller grey spherical formations. The matrix consists of needle-like tempered martensite, Fig. 1b. No proeutectoid phases were identified at the grain boundaries. It indicates that the heat treatment before the plasma nitriding has been well performed. The detailed examination, reported in [12], revealed two basic types of martensite: the dislocation type with a high density of dislocations and the twinned martensite. The presence of the abovementioned carbides was also confirmed in [12].

Light micrographs in Figs. 2-5 show the nitrided surface regions formed at various processing conditions. They differ from the no-nitrided material mainly in the darkness of appearance, which is connected by 


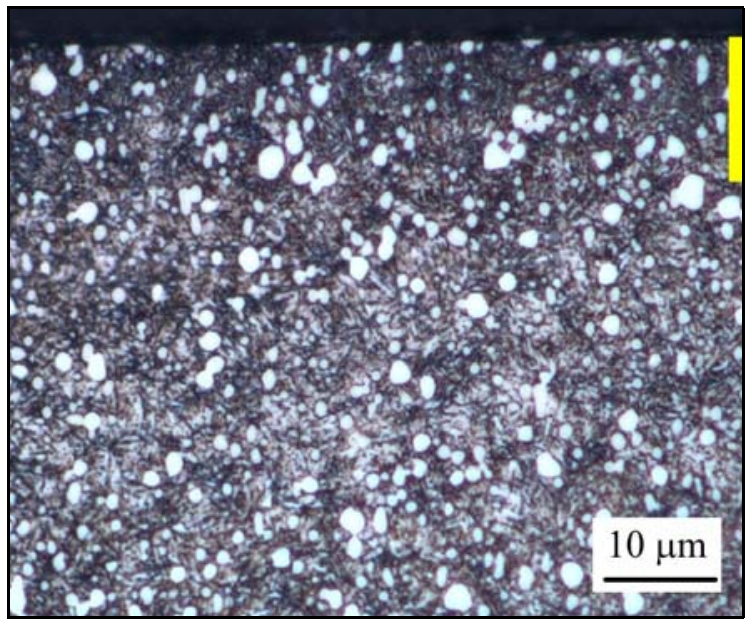

Fig. 2. Light micrograph showing the microstructure of the nitrided region developed at $470{ }^{\circ} \mathrm{C}$ for $30 \mathrm{~min}$.

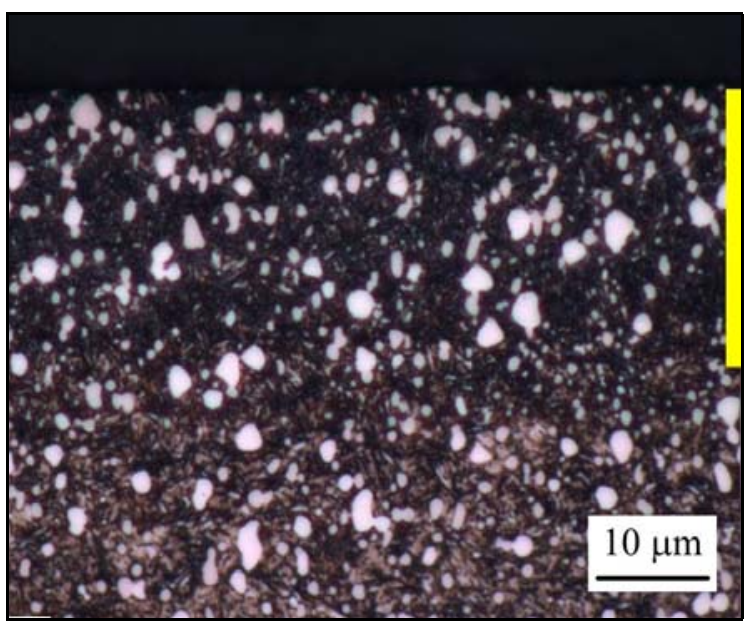

Fig. 3. Light micrograph showing the microstructure of the nitrided region developed at $470{ }^{\circ} \mathrm{C}$ for $120 \mathrm{~min}$.

presence of fine precipitates. In the specimens processed at $470^{\circ} \mathrm{C}$, neither the compound layer nor the nitride network was found, Figs. 2, 3. On the other hand, these structural constituents are clearly visible in the material processed at $500{ }^{\circ} \mathrm{C}$ for $60 \mathrm{~min}$ and $530^{\circ} \mathrm{C}$ for $120 \mathrm{~min}$, respectively, Figs. 4 and 5 . On the micrographs in Figs. 2-4, there is also the nitrogen diffusion depth marked out by yellow band on the right hand side. On the micrograph in Fig. 5, there is not the diffusion region highlighted since it reaches deeper than the effective scale of the micrograph.

The microstructure of nitrided region developed at $500{ }^{\circ} \mathrm{C}$ for $60 \mathrm{~min}$ is shown in SEM micrograph, Fig. 6. The material consists of the matrix and two basic types of secondary phases. One of the secondary type particles is grey and significantly larger while the others are much smaller and appear in a black colour.

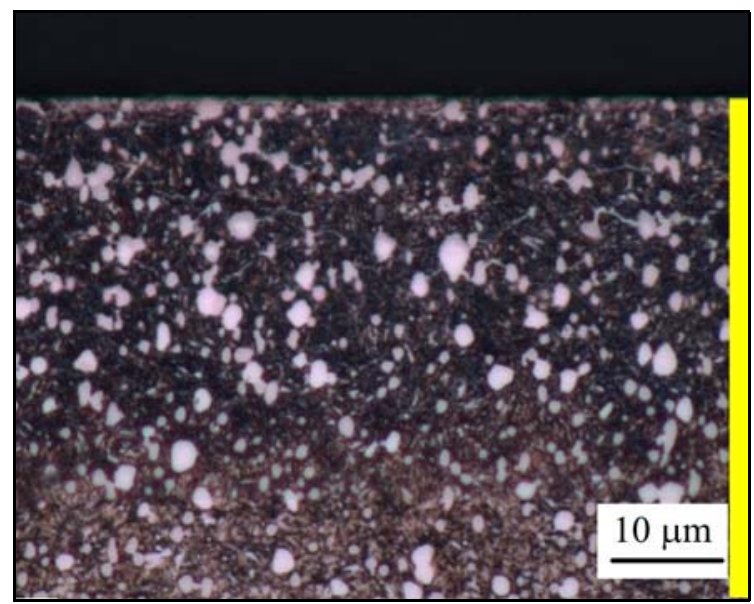

Fig. 4. Light micrograph showing the microstructure of the nitrided region developed at $500^{\circ} \mathrm{C}$ for $60 \mathrm{~min}$.

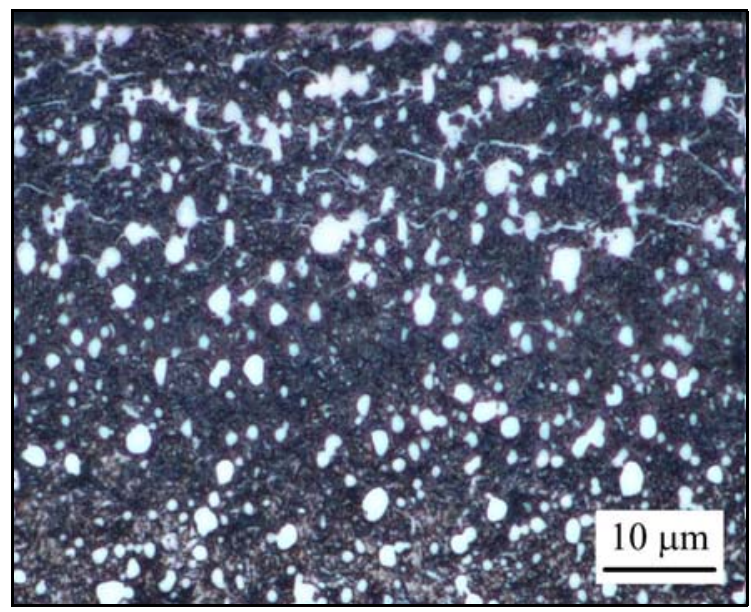

Fig. 5. Light micrograph showing the microstructure of the nitrided region developed at $530^{\circ} \mathrm{C}$ for $120 \mathrm{~min}$.

In the matrix there are the original austenite grains visible since the nitride network decorates them. After the ion polishing, the regime COMPO revealed that the larger grey particles were not homogeneous with respect to their chemical composition. Some of them, mainly those closer to the surface look much darker while the carbides located in larger distance from the surface show an apparent darker ring and brighter central part.

EDS mapping shows that the grey and larger particles are rich in chromium and iron and contain also a significant portion of nitrogen, Fig. 7. On the other hand their carbon content is considerably lower. Moreover, they also contain some portion of the vanadium. These symptoms confirm that it concerns the originally chromium rich $\mathrm{M}_{7} \mathrm{C}_{3}$ carbides. After the nitriding they became the $\mathrm{M}_{7}(\mathrm{C}, \mathrm{N})_{3}$ carbo-nitrides. De- 


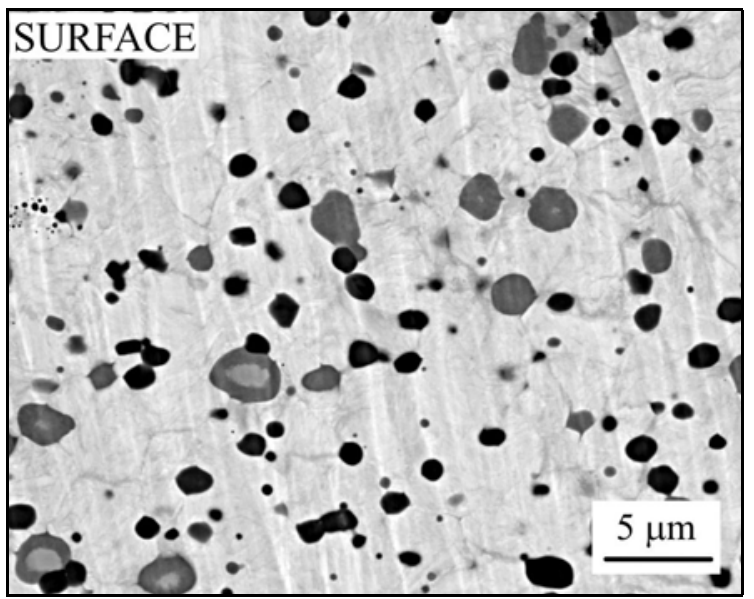

Fig. 6. SEM micrograph showing the microstructure of the nitrided region developed at $500{ }^{\circ} \mathrm{C}$ for $60 \mathrm{~min}$.

tailed EDS-analysis fixed the following content of main elements in this phase (in wt.\%): $2.49 \% \mathrm{C}, 10 \% \mathrm{~N}$, $10.7 \% \mathrm{~V}, 33.34 \% \mathrm{Cr}, 40.45 \%$ Fe. In some cases, these particles are not completely through-nitrided and in their central region, the nitrogen-free area is evident. The smaller black formations are rich in vanadium and carbon. They contain also small portion of chromium and nitrogen but only very limited amount of iron. This indicates that these formations are the MC-type carbides enriched by nitrogen.

The surface nitrogen content increases with increased processing temperature and/or processing time, see Table 1. Even a low temperature process carried out for short time induced nitrogen saturation up to $2 \mathrm{wt} . \%$. The maximal concentration reaches up to $7.5 \mathrm{wt} . \%$ when the steel has been processed at the temperature of $530^{\circ} \mathrm{C}$ for $120 \mathrm{~min}$. The depth profile shows a "plateau", with a constant concentration of nitrogen ranging around the value of $7.5 \mathrm{wt} . \%$, which takes into a relatively considerable depth. This may indicate that the value of $7.5 \mathrm{wt} . \%$ of nitrogen is a standard nitrogen uptake corresponding to the given nitriding conditions, mainly the nitrogen potential of a low-pressure atmosphere, negative substrate bias, etc.

Also the depth of nitrogen diffusion increases up to the maximal thickness of $56 \mu \mathrm{m}$ for the material processed at $530^{\circ} \mathrm{C}$ for $120 \mathrm{~min}$.
The carbon surface content did not change practically for the material processed at the temperature of $470{ }^{\circ} \mathrm{C}$ for $30 \mathrm{~min}$. On the other side, dramatic changes in the carbon content were determined for other specimens. Generally, the surface content of carbon was lower than the nominal steel content and it increased inwards to the core to a maximal value that exceeded the actual steel content clearly. Beyond the concentration peak, the C-content decreased slightly to the nominal alloy composition. For each specimen, the position of the maximum peak corresponds relatively well with the maximal nitrogen diffusion depth.

Diffractograms, Fig. 8a-c, recorded after plasma nitriding at various regimes revealed that the nitrided regions are composed of $\alpha$-solid solution, $\mathrm{M}(\mathrm{C}, \mathrm{N})$ -carbo-nitrides and iron-based nitrides. The nature of nitrides and their quantity were indentified to be different for the material processed at different temperature/time combinations. The $\mathrm{CrN}$-nitrides as well as the $\mathrm{M}_{7} \mathrm{C}_{3}$-phase did not give a diffraction signal. The explanation can be based on the expected penetration depth of the Co-radiation, which is about 1.5 $\mu \mathrm{m}$. For the specimens with the presence of the compound layer on the surface, Fig. 8b,c, the diffraction is then given mainly from the constituents forming this layer, e.g. $\mathrm{Fe}_{4} \mathrm{~N}-$ and $\mathrm{Fe}_{3} \mathrm{~N}$-phase, respectively, and the major phase that is the $\alpha$-solid solution. Moreover, it should be taken into consideration that the $\mathrm{M}_{7} \mathrm{C}_{3}$ -carbide undergoes the dissolution in austenite much more than the MC. Therefore, the probability to record a diffraction signal from $\mathrm{M}_{7} \mathrm{C}_{3}$ is low. For the specimen processed at $470^{\circ} \mathrm{C}$ for $30 \mathrm{~min}$, no compound layer was identified, and this is the principal explanation why the diffraction peaks from the nitrides are very slight, Fig. 8a.

The saturation of original phases with nitrogen and formation of nitrides increase the hardness, Fig. 9. Measurements revealed relatively high near-surface hardness even for the specimens treated at lower temperature and/or short dwell time. For the specimens processed at higher temperature and/or longer dwell time, the near surface microhardness increased rapidly and its maximal values exceeded $1600 \mathrm{HV} 0.05$. The main difference between specimens processed by various nitriding conditions is that the hardness after processing at lower temperature drops down at a short

Table 1. Surface content of interstitials, nitrogen diffusion depth and carbon redistribution vs. nitriding parameters

\begin{tabular}{lcccc}
\hline Nitriding & $\begin{array}{c}\text { Nitrogen surface } \\
\text { content (wt.\%) }\end{array}$ & $\begin{array}{c}\text { Carbon surface } \\
\text { content (wt.\%) }\end{array}$ & $\begin{array}{c}\text { Nitrogen diffusion } \\
\text { depth }(\mu \mathrm{m})\end{array}$ & $\begin{array}{c}\text { Maximal carbon } \\
\left.{\text { concentration } / \text { depth }^{(w t . \% ~} \mu \mathrm{m}}^{-1}\right)\end{array}$ \\
\hline $470^{\circ} \mathrm{C} / 30 \mathrm{~min}$ & $1.84 \pm 0.39$ & $2.06 \pm 0.31$ & 13 & - \\
$470^{\circ} \mathrm{C} / 120 \mathrm{~min}$ & $3.61 \pm 0.24$ & $1.13 \pm 0.09$ & 25 & $2.98 / 17$ \\
$500^{\circ} \mathrm{C} / 60 \mathrm{~min}$ & $5.37 \pm 0.7$ & $1.13 \pm 0.2$ & 46 & $3.48 / 44$ \\
$530^{\circ} \mathrm{C} / 120 \mathrm{~min}$ & $7.52 \pm 0.66$ & $1.76 \pm 0.13$ & 56 & $2.54 / 36$ \\
\hline
\end{tabular}


distance from the surface. On the other hand, only a slight hardness decrease was observed in the specimen processed at $530^{\circ} \mathrm{C}$ for $120 \mathrm{~min}$. These results correspond well with the established nitrogen diffusion depth, Table 1. Differences in microhardness depth profiles are also reflected in the surface hardness, which is markedly lower for the specimens pro- cessed at $470{ }^{\circ} \mathrm{C}(882 \mathrm{HV} 10)$ than for those nitrided at $530^{\circ} \mathrm{C}(1122 \mathrm{HV} 10)$.

\section{Discussion}

The initial structure of the Vanadis 6 steel before

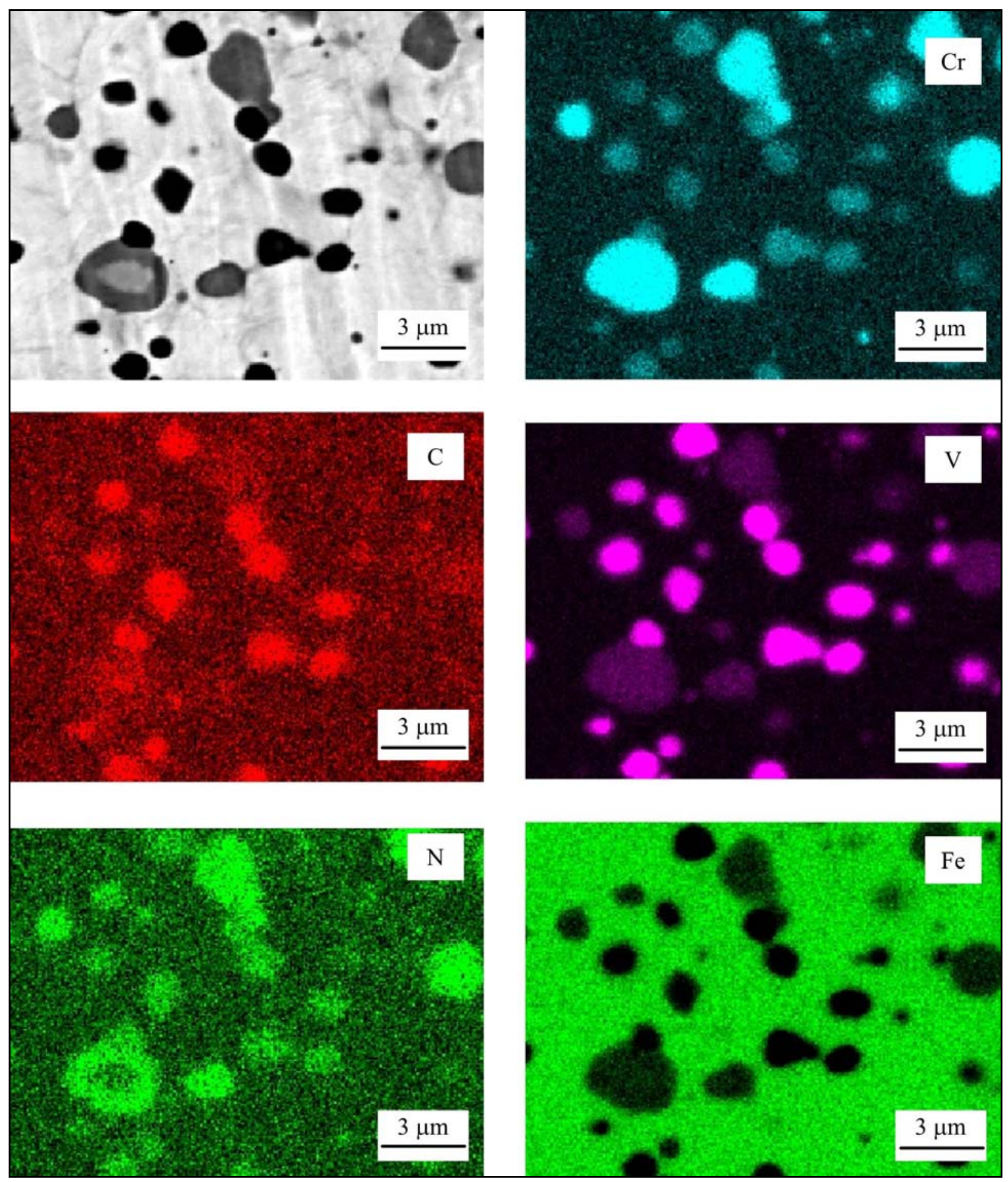

Fig. 7. EDS mapping of main elements from the Fig. 6. 

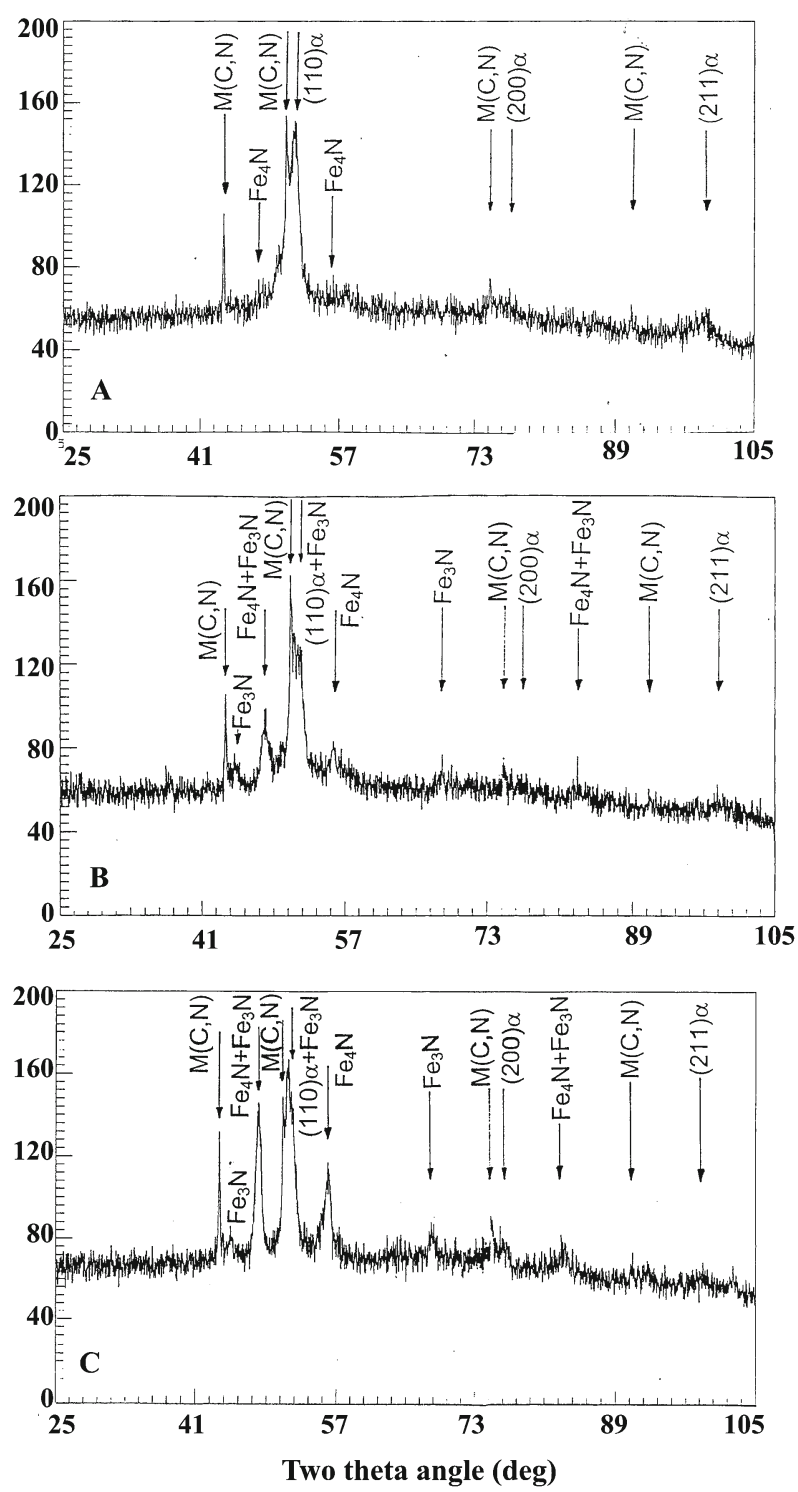

Fig. 8. X-ray patterns from the nitrided regions: (a) nitrided at $470{ }^{\circ} \mathrm{C}$ for $30 \mathrm{~min}$, (b) nitrided at $500^{\circ} \mathrm{C}$ for $60 \mathrm{~min}$, (c) nitrided at $530^{\circ} \mathrm{C}$ for $120 \mathrm{~min}$.

nitriding is formed in the process, which includes the manufacturing of the steel and its heat treatment. The steel manufacturing process included the powder preparation via rapid solidification technique and subsequent consolidation by hot isostatic pressing. Therefore, the as-received microstructure of the material consists of the pearlite and fine, uniformly distributed $\mathrm{M}_{7} \mathrm{C}_{3}$ and $\mathrm{MC}$ carbides.

In the $\mathrm{Cr}$-C equilibrium diagram, the $\mathrm{Cr}_{7} \mathrm{C}_{3}$-phase contains around 9 wt. $\%$ of carbon. In ledeburitic steels it appears mainly in the hexagonal structure [13]. Chromium can be substituted in the carbides by iron, up to the $\mathrm{Cr}$ : Fe ratio of approx. 1: 1, and also by other elements but in a substantially smaller extent. For example, vanadium can dissolve in the $\mathrm{M}_{7} \mathrm{C}_{3^{-}}$

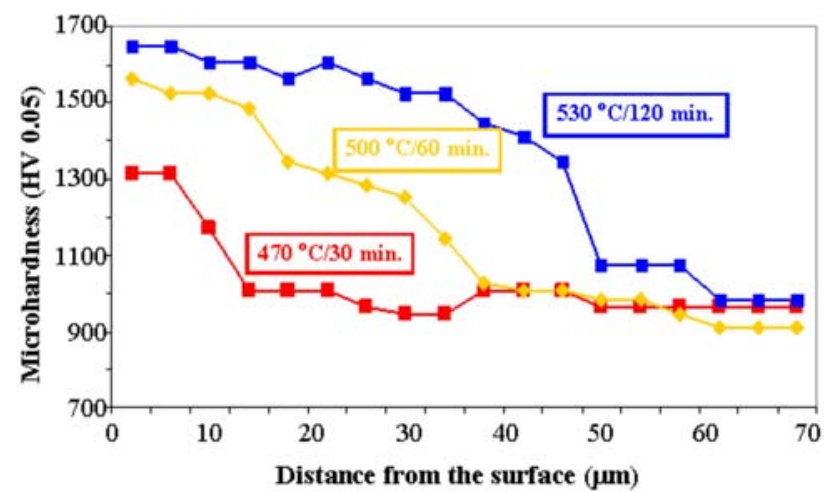

Fig. 9. Microhardness depth profiles for the specimens processed with various nitriding parameters.

-phase up to approx. $10 \mathrm{wt} . \%$ [14]. There are not, however, relevant data about the stoichiometry of the carbide in ledeburitic steels. Only for the Fe-2.1\%C$-20 \% \mathrm{Cr}-7 \% \mathrm{~V}$ alloy it was reported that the as-cast $\mathrm{M}_{7} \mathrm{C}_{3}$ carbides contained between 8 and $10 \mathrm{wt} . \% \mathrm{C}$ [15]. Therefore it seems that at least for this alloy the phase is semi-stoichiometric. During the heating up to the austenitizing temperature a part of the $\mathrm{M}_{7} \mathrm{C}_{3^{-}}$-phase undergoes dissolution in the austenite. Second part of the carbides remains not dissolved, whereas some of them undergo slight coarsening [15]. Nevertheless, no experimental work has been focused to an investigation of possible changes of chemical composition of the carbide up to now. The capability of the $\mathrm{M}_{7} \mathrm{C}_{3}$-carbide to uptake of some amount of nitrogen without a need to release the carbon atoms is thus not entirely clear yet. For the Vanadis 6 steel, however, current EDS measurements gave doubtless information - after some period from the beginning of the nitriding, the nitrogen substitutes partly the carbon in the $\mathrm{M}_{7} \mathrm{C}_{3}$ carbide and the carbon atoms undergo a redistribution with a peak far away the surface, Table 1. What is, however, not clear yet, is the contrast change of the $\mathrm{M}_{7} \mathrm{C}_{3}$ (or $\mathrm{M}_{7}(\mathrm{C}, \mathrm{N})_{3}$ ) particles caused by the nitriding, Figs. 6, 7. One would expect that this was due to the nitrogen input into the original carbide. But, the atomic number of the nitrogen is higher than that of carbon. Therefore also other changes in the chemical composition of the carbides could be expected. Anyway, the intensity of the changes in the chemical composition of the $\mathrm{M}_{7} \mathrm{C}_{3}$-phase during the nitriding will require further investigations.

The MC-phase is based mainly on the vanadium in ledeburitic steels. Normally, the MC-carbide is sub-stoichiometric and the $\mathrm{C} / \mathrm{V}$ ratio ranges between 0.73 and 0.88 [16]. Increased carbon content from the $\mathrm{C} / \mathrm{V}=0.73$ to $\mathrm{C} / \mathrm{V}=0.88$ induces an increase of the lattice parameter from $0.4126 \mathrm{~nm}$ to $0.4166 \mathrm{~nm}[16$, 17]. The MC-carbide can contain also other elements but in a significantly smaller amount compared to the 
$\mathrm{M}_{7} \mathrm{C}_{3}$-phase. For instance, chromium can be dissolved in the MC-phase up to $11 \mathrm{wt} . \%$ and during the austenitizing, a part of chromium can be released into the austenite [18-22]. Also for the MC-carbide, no investigations have been devoted to establish what happens with the carbide during the nitriding. It seems, however, that the MC-phase has some capability to absorb the nitrogen without a need to release the carbon since it is sub-stoichiometric as in soft-annealed state after heat treatment of materials.

The matrix of the material before the nitriding consists of the tempered martensite with a low carbon content. The contribution of the matrix for the total nitrogen uptake is limited by the solid solubility of the nitrogen in the $\alpha$-phase (approx. $0.1 \mathrm{wt} . \%$ ).

During the nitriding of the ledeburitic steels, either a nitride network along original austenite grains or continuous compound layer on the surface can be formed. The situation, however, is more difficult since in most cases both $\gamma^{\prime}$ - and $\varepsilon$-phase can be detected by $\mathrm{X}$-ray diffraction but the establishment of their portion is practically impossible. Therefore some portion of nitrogen is spent also for the formation of these compounds, mainly when the material is nitrided at higher temperature and/or longer processing time.

Previous TEM-investigations [12] confirmed the formation of disperse $\mathrm{Fe}_{4} \mathrm{~N}$ and $\mathrm{CrN}$ nitrides during the nitriding of the Vanadis 6 steel. The formation of $\mathrm{VN}$-nitrides has also been expected but they were not detected [12]. Vives Dias et al. [9] reported that in pure Fe-V system, the VN-phase is formed as small platelets, with a thickness of several atomic planes and a length of few nanometers, coherent with the ferritic matrix. Such small particles did not give diffraction and they were detected only after an additional thermal treatment, when they underwent a significant growth. Moreover, the nitriding temperature was $580^{\circ} \mathrm{C}$, e.g. much higher than that of discussed experimental works, and the processing time was $10 \mathrm{~h}$ and longer, e.g. again much longer than that of actual experiments. Finally, nitrided F-V alloy consisted only of one phase, ferrite, and it did not contain carbides or other phases. On the other hand, the most part of vanadium is incorporated in MC-carbides in the case of the Vanadis 6 steel. The MC-carbides remain stable also after austenitizing and the release of the vanadium into the austenite is almost negligible. Therefore, the potential for the formation of VN-phase is strongly limited, which gives a second possible explanation why it was not detected in [12]. The nitrogen is then probably spent only for the formation of $\mathrm{Fe}_{4} \mathrm{~N}-$ and $\mathrm{CrN}$ -nitrides and to assess amount of incorporated nitrogen, the volume fraction of these nitrides should be determined in the future. However, the no-existence of vanadium nitrides in the investigated material should be confirmed in the future, as by the extension of the scale of the nitriding parameters for the processing of samples so by the use of TEM on thin foils prepared by precise technique of argon ion bombardment.

In $[7,9]$ it is reported that compressive strain fields are formed around the nitrides of alloying elements, e.g. chromium and vanadium. These stresses are due to the misfit of the lattice of the nitrides and the matrix. After the nitrides become larger and incoherent, the compressive stresses tend to decrease. However, as reported in abovementioned works the strain fields located around the precipitates can absorb some portion of nitrogen. So-called nitrogen excess then occurs and it makes of about $10 \%$ of the total nitrogen uptake of the material. Also in [23] the presence of high compressive macro-stresses was determined for the Vanadis 6 steel after the plasma nitriding at the temperatures in the range $470-530^{\circ} \mathrm{C}$ and processing times from 30 to $240 \mathrm{~min}$. The value of the stresses was more than $1000 \mathrm{MPa}$ for the material processed at $470^{\circ} \mathrm{C}$ for $30 \mathrm{~min}$ and it increased slightly to $1300 \mathrm{MPa}$ for the steel nitrided at $530{ }^{\circ} \mathrm{C}$. This indicates that also in nitrided Vanadis 6 steel, the strain fields exist around the nitrides and some nitrogen excess can be expected in a similar way to investigations in $[7,9]$.

The total nitrogen uptake of nitrided Cr-V ledeburitic steels can be thus given as

$$
\begin{aligned}
\mathrm{N}= & \mathrm{N}_{\alpha}+\mathrm{N}_{\mathrm{MC}}+\mathrm{N}_{\mathrm{M} 7 \mathrm{C} 3}+\mathrm{N}_{\text {nitrides }}+\mathrm{N}_{\text {network }}+ \\
& +\mathrm{N}_{\text {compound }}+\mathrm{N}_{\text {strain }},
\end{aligned}
$$

where $\mathrm{N}_{\alpha}$ is the nitrogen dissolved in the tempered martensite, $\mathrm{N}_{\mathrm{MC}}$ is the nitrogen absorbed by the MC-phase, $\mathrm{N}_{\mathrm{M} 7 \mathrm{C} 3}$ is the amount of nitrogen in $\mathrm{M}_{7} \mathrm{C}_{3}$ -phase, $\mathrm{N}_{\text {nitrides }}$ is the nitrogen incorporated in the nitrides of alloying elements $(\mathrm{Cr}, \mathrm{V})$ or iron, but without the continuous network or compound layer on the surface, $\mathrm{N}_{\text {network }}$ is the nitrogen content in the network (if it is formed), $\mathrm{N}_{\text {compound }}$ is the part of the nitrogen incorporated in the compound layer (if occurs) and $\mathrm{N}_{\text {strain }}$ is the nitrogen excess due to the strain fields around the precipitates of nitrides.

Three main situations can be found in the case of $\mathrm{Cr}-\mathrm{V}$ ledeburitic tool steels:

a) Neither the compound layer nor the network along the grain boundaries is formed. This is the case of the material processed at $470{ }^{\circ} \mathrm{C}$ for $30 \mathrm{~min}$. Equation (1) is then reduced to the contributions of nitrogen dissolved in the martensite, nitrogen incorporated in carbides and nitrides and nitrogen excess due to the strain fields. As evident from Table 1, no significant carbon redistribution was found in the processed material. It indicates that also the contribution of $\mathrm{N}_{\mathrm{M} 7 \mathrm{C} 3}$ to the total nitrogen uptake is minimal and the nitrogen is probably incorporated only in the MC-carbides. The situation becomes more difficult for the steel processed at $470^{\circ} \mathrm{C}$ for $120 \mathrm{~min}$. Compared to the material processed for shorter time, higher nitrogen content in the nitrided region and considerable carbon redis- 
tribution were found, see Table 1. As a principal explanation, the carbon replacement by nitrogen in the $\mathrm{M}_{7} \mathrm{C}_{3}$-phase can be considered.

b) In some cases, nitride network can be formed along the grain boundaries, but without a continuous compound layer on the surface. The contribution of $\mathrm{N}_{\text {network }}$ into the total nitrogen uptake of the material should be taken into consideration. However, based on practical experiences it is very difficult to determine the volume fraction of the network with an acceptable accuracy.

c) If also the compound layer is formed on the surface (the case of the material processed at 500 and $530^{\circ} \mathrm{C}$ ), the contribution of $\mathrm{N}_{\text {compound }}$ should be added into Eq. (1). Nevertheless, the determination of the $\mathrm{N}_{\text {compound }}$ will cause obstacles since, as mentioned above, both $\gamma^{\prime}$ - and $\varepsilon$-nitrides are mostly present, see Fig. 8.

Based on current analysis it seems that the development of the phase constitution due to the nitriding begins with the saturation of the $\alpha$-solid solution and other original phases with nitrogen. Firstly, the MC-phase is saturated. After that, the $\mathrm{M}_{7} \mathrm{C}_{3}$ absorbs the nitrogen but the nitrogen uptake proceeds simultaneously with the carbon release and its diffusion into bulk. After the solid solubility limit of nitrogen in $\alpha$-phase is exceeded, also fine nitride particles are formed. Around these particles, the strain fields are formed. This is connected with the macro-stresses that exceed $1000 \mathrm{MPa}$, substantial hardness increase and probably with some additional nitrogen uptake (nitrogen excess), as reported by Hosmani and Vives Dias $[8,9]$. Further prolonging the processing time or increasing the temperature leads to the formation and growth of the nitride network and continuous compound layer on the surface. These structural constituents are composed mostly of both basic phases, e.g. $\mathrm{Fe}_{4} \mathrm{~N}-$ and $\mathrm{Fe}_{3} \mathrm{~N}$-nitride.

\section{Conclusions}

After the standard heat treatment procedure and before the nitriding, the microstructure of the Vanadis 6 ledeburitic steel consists of a matrix, composed of a tempered martensite, and $\mathrm{M}_{7} \mathrm{C}_{3^{-}}$and $\mathrm{MC}$-carbides.

The development of phases due to the nitriding begins with the saturation of tempered martensite with nitrogen. After the solid solubility of the nitrogen in tempered martensite is exceeded, firstly the MC-carbides and afterwards the $\mathrm{M}_{7} \mathrm{C}_{3}$-carbides undergo the nitrogen saturation. Subsequently, the nitride network and continuous compound layer appear on the surface and also iron- and chromium-nitride particles are formed. As a contribution of the total nitrogen uptake by the material, also the nitrogen "excess" due to the strain field around the iron- and chromium-nitride particles can be expected since the macro-stresses after the nitriding exceed $1000 \mathrm{MPa}$.

The nitrogen amount increases with an increase of the processing temperature and/or the processing time up to 7.5 wt.\%. The input of nitrogen atoms into the surface induces carbon redistribution with its repulsion away from the surface. It seems that the main sources for the carbon redistribution are the $\mathrm{M}_{7} \mathrm{C}_{3^{-}}$ -carbides, whereas the dominant part of carbon is substituted by nitrogen in this phase. Other, but minor source for the formation of the carbon content peak far away from the surface is the redistribution of carbon from the martensite.

From the macroscopical point of view, the saturation of the Vanadis 6 steel with nitrogen has a response in considerable increased surface hardness. The surface hardness increase ranges between 180 and 420 HV 10, depending on the nitriding conditions used for the material processing.

\section{Acknowledgement}

Author wishes to thank the Ministry of Education and Youth of the Czech Republic for the financial support for the solution of the Project Eureka E!3437 PROSURFMET.

\section{References}

[1] BERGMANN, E.: Traitement Thermique, 5, 1996, p. 41.

[2] SPIES, H. J.-HOECK, K.-LARISCH, B.: HTM, 51, 1996, p. 222.

[3] JURČI, P.-PANJAN, P.: Metal Powder Report, 61, 2006, p. 28.

[4] JURČI, P.-HUDÁKOVÁ, M.: Materials and Technology, 42, 2008, p. 197.

[5] SOMERS, M. A. J.-MITTEMEIJER, E. J.: Metall. Mater. Trans. A, 26, 1995, p. 57. doi:10.1007/BF02669794

[6] SCHACHERL, R. E.-MITTEMEIJER, E. J.: HTM, 59,2004, p. 312.

[7] VIVES DIAZ, N. E.-SCHACHERL, R. E.-ZAGONEL, L. F.-MITTEMEIJER, E. J.: Acta Mater., 56, 2008, p. 1196.

[8] HOSMANI, S. S.-SCHACHERL, R.-MITTEMEIJER, E. J.: Acta Mater., 54, 2006, p. 2783. doi:10.1016/j.actamat.2006.02.017

[9] VIVES DIAZ, N. E.-HOSMANI, S. S.-SCHACHERL, R. E.-MITTEMEIJER, E. J.: Acta Mater., 56, 2008, p. 4137.

[10] JURČI, P.-HNILICA, F.: Powder Metallurgy Progress, 3, 2003, p. 10.

[11] Pearson's Handbook - Crystallograhic Data for Intermetallic Phases. Materials Park, Ohio, ASM International 1997.

[12] JURČI, P.-HNILICA, F.-SUCHÁNEK, J.-STOLAR̆, P.: Materials and Technology, 38, 2004, p. 13. 
[13] RAYNOR, G. V.-RICIN, V. G.: Phase Equilibria in Iron Ternary Alloys, Phase Diagrams of Ternary Iron Alloys - Part 4. London, The Institute of Metals 1998.

[14] HAMAR-THIBAULT, T. S.-ADNANE, L.-KESRI, R.: J. Alloys and Compounds, 317-318, 2001, p. 311. doi:10.1016/S0925-8388(00)01362-1

[15] JURČI, P.: Příprava a studium vlastností rychle ztuhlých prášků a kompaktů systému Fe-C-Cr-V. [PhD Thesis]. Trnava, MtF STU 1996.

[16] SAMSONOW, G. V.-UPADCHAJA, G. S.-NEŠPOR, V. S.: Fizičeskoje materialovedenije karbidov. Kijev, Naukova Dumka 1974 (in Russian).

[17] BILlinghAM, J.-BELL, P. S.-LEWIS, M. H.: Acta Cryst., A28, 1972, p. 602. doi: $10.1107 / \mathrm{S} 0567739472001524$
[18] FREDRIKSSON, H.-HILLERT, M.-NICA, M.: Scand. J. Metall., 8, 1979, p. 115.

[19] VERSACI, R. A.: J. Mater. Sci. Lett., 7, 1988, p. 273. doi:10.1007/BF01730195

[20] ADELT, M.-HAMMERBAUER, P.-HOLLER, M.: Hutnické listy, 10, 1989, p. 714 (in Czech).

[21] PIOTRKOWSKI, R.-VERSACI, R. A.: J. Mater. Sci. Lett., 11, 1992, p. 390. doi:10.1007/BF00728718

[22] STILLER, K.-SVENSSON, L. E.-HOWELL, P. R.: Acta Metall., 32, 1984, p. 1457. doi:10.1016/0001-6160(84)90092-0

[23] JURČI, P.-HUDÁKOVÁ, M.: In: Proceedings of the 16th Int. Metallurgical and Materials Conference METAL 2007. Ostrava, Tanger, s.r.o. 2007, CD-ROM. 